The subject is asked to choose the appropriate pair of holes and their distance apart is noted. The card is then taken away and handed back the other way round, and he chooses again. This performance is repeated five or more times to give material for statistical analysis. It will be found that if the patient is of average intelligence his answers will seldom vary by more than $\pm 0.5 \mathrm{~mm}$., once he has learned the method.

The writer, working with oral Dibenzyline (a sympathetic blocking drug), found that in six out of ten cases the miosis produced was highly significant $(P<\cdot 001)$ and in two cases it was significant $(P<\cdot 01)$. The two remaining subjects showed no significant change. One was of poor intelligence and was obviously guessing, as shown by his perseveration at some times, and his wide scatter at others. The other had abnormally small pupils which probably made further miosis difficult to produce. (The analysis of variance and the " $T$ " test were both used and they agreed fairly closely.)

It was noteworthy that, when the effects of Benzedrine $(10 \mathrm{mg}$.) were measured in another series, no significant changes occurred in the majority of subjects, who had fairly large pupils. Two subjects with small pupils did, however, produce a significant degree of mydriasis. It is suggested, therefore, that it is easier to measure pupil changes directed towards their mean position than away from it, so that, as most subjects appear to have a pupil size of about $5 \mathrm{~mm}$. the method appears more sensitive for tests oï miotic activity.

It is suggested that this simple instrument is of considerable value for research work upon the physiology and pharmacology of the autonomic nervous system. It might also be of some slight value in neurology and ophthalmology, and perhaps also in the study of morphinism.

\title{
LARGE CONCAVE MIRROR FOR INDIRECT OPHTHALMOSCOPY*
}

\author{
BY \\ H. NEAME \\ London
}

THE mirror is concave, $9 \mathrm{~cm}$. in diameter, of the type used by aural surgeons, but with a focal length of $50 \mathrm{~cm}$. instead of the usual $30 \mathrm{~cm}$. It was recommended a few years ago for indirect ophthalmoscopy for fundus examination by an American ophthalmic surgeon who had found that it gave very good fundus illumination in many cases when the pupil was dilated with a mydriatic. When used with a Hamblin dark-room lamp, it seemed to illuminate as brilliantly as with Weve's 500-watt lamp in an enclosed reflector as recommended for cases of detached retina. It was of no use with an active pupil. 